\title{
Off-Label Coverage of High-Cost Drugs by Independent Charity Patient Assistance Programs
}

\author{
So-Yeon Kang, MPH, MBA ${ }^{7}$, Mariana P. Socal, MD, $P h D^{7}$, Ge Bai, $P h D, C P A^{7,2}$, and \\ Gerard F. Anderson, $P h D^{7}$
}

'Department of Health Policy and Management, Bloomberg School of Public Health, Johns Hopkins University, Baltimore, MD, USA; ${ }^{2}$ Johns Hopkins Carey Business School, Bernstein-Offit Building 353, 1717 Massachusetts Ave NW, Washington, DC, 20036, USA.

$J$ Gen Intern Med 36(2):555-6

DOI: $10.1007 / \mathrm{s} 11606-020-05682-9$

(c) Society of General Internal Medicine 2020

\section{INTRODUCTION}

Independent charity patient assistance programs are funded by pharmaceutical companies to help eligible patients cover their out-of-pocket costs for prescription drugs. ${ }^{1}$ Pharmaceutical companies are prohibited from advertising or distributing information about off-label uses of their products but commonly suggest off-label uses in their direct-to-consumer advertisements for certain drugs. ${ }^{2,3}$ Independent charity patient assistance programs had been prohibited from offering financial assistance for off-label uses until 2014, ${ }^{4}$ when the US Department of Health and Human Services relaxed the guidelines to allow these programs to cover less expensive drugs for offlabel uses. ${ }^{5}$ The extent to which independent charity patient assistance programs have covered off-label uses of prescription drugs and the types of these covered drugs have not been examined.

\section{METHODS}

Using the GuideStar nonprofit organization database, we identified the two largest US independent charity foundations-PAN foundation and Healthwell foundation - that allocated more than $50 \%$ of their revenue to patient assistance programs in 2017, disclosed the names of covered drugs, and were listed on the Medicare website. ${ }^{1}$ Other independent charities did not meet these inclusion criteria. ${ }^{1}$

We reviewed all the 138 disease-specific patient assistance programs listed on these two charities' websites in September 2019. Among the drugs covered by the programs, we focused on high-cost drugs, defined as specialty tier $(>\$ 8040$ a year) in Medicare Part D. Since these charities are not permitted to narrow the scope of a program by stage or specific symptoms, ${ }^{5}$

Received January 4, 2020

Revised January 4, 2020

Accepted January 23, 2020

Published online February 24, 2020 we compared disease names (e.g., bladder cancer) to the FDAapproved indications to identify off-label coverage.

For the drug-program pairs that we identified as off-label coverage, we analyzed whether the indication was supported by each of three clinical compendia: American Hospital Formulary Service ${ }^{\circledR}$ Drug Information, DrugDex ${ }^{\circledR}$, and National Comprehensive Cancer Network (NCCN) guidelines for cancer treatment. These three clinical compendia are routinely used by Medicare and major insurers when determining drug coverage for indications not included in the FDA-approved label. ${ }^{6}$ Two researchers independently reviewed all drugprogram pairs and matched them to compendia recommendations.

\section{RESULTS}

We identified 251 high-cost drugs covered by at least one of the 138 disease-specific patient assistance programs provided by the two charities that we examined. Patient assistant programs' coverage of prescription drugs for off-label uses varies substantially across drugs. Among the 251 drugs, 60 drugs (24\%) were for off-label uses and all of them were covered by multiple programs. The 60 drugs and the programs covering them represented 401 unique drug-program pairs. Among the 401 drug-program pairs, 190 pairs (47\%) were for off-label uses. Of these 190 pairs for off-label uses, 83 (44\%) were not supported by any of the three clinical compendia that we examined (Table 1).

Cancer drugs were most likely to be covered for off-label uses. Six out of nine patient assistance programs covering Nexavar (sorafenib) were for off-label uses, and no clinical

Table 1 Drug-Patient Assistance Program Pairs for Off-Label Uses

\begin{tabular}{llll}
\hline \hline $\begin{array}{l}\text { No. of } \\
\text { drugs }\end{array}$ & $\begin{array}{l}\text { No. of drug- } \\
\text { program } \\
\text { pairs }\end{array}$ & $\begin{array}{l}\text { No. of drug- } \\
\text { program pairs } \\
\text { for off-label uses } \\
(\%)\end{array}$ & $\begin{array}{l}\text { No. of drug-program } \\
\text { pairs for off-label } \\
\text { uses that were not } \\
\text { supported by any of } \\
\text { three clinical } \\
\text { compendia* }(\%)\end{array}$ \\
\hline 60 & 401 & $\begin{array}{l}190 \text { out of } 401 \\
(47 \%)\end{array}$ & 83 out of $190(44 \%)$ \\
\hline
\end{tabular}

*American Hospital Formulary Service ${ }^{\circledR}$ Drug Information, DrugDex®, and National Comprehensive Cancer Network (NCCN) guidelines for cancer drugs 


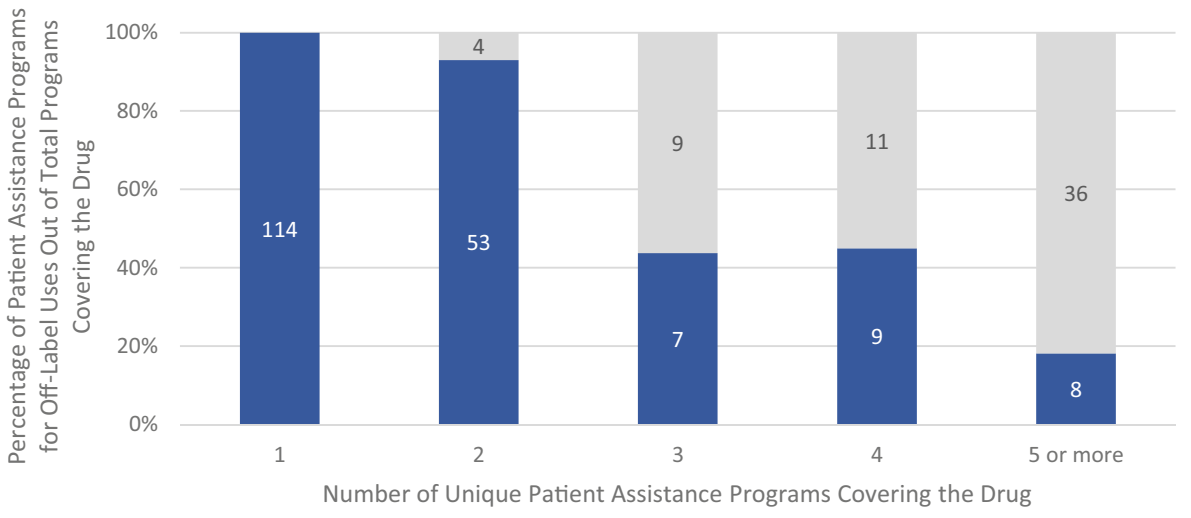

- Patient Assistance Programs for Labeled Uses_ Patient Assistance Programs for Off-Label Uses

Figure 1 Number and percentages of high-cost drugs covered for off-label uses by patient assistance programs.

compendium supported any of these uses. However, not all cancer drugs received off-label support. Opdivo (nivolumab), for example, was not covered for any off-label uses.

As presented in Figure 1, the likelihood of a drug being covered by any patient assistance programs for off-label uses was positively associated with the total number of different programs covering the drug. Among the 167 drugs covered by one or two patient assistance programs, only four drugs ( $2 \%)$ were covered for off-label uses; among the 44 drugs covered by five and more programs, 36 drugs $(82 \%)$ were covered for off-label uses.

Among the 138 patient assistant program websites we examined, no program published any disclaimer that the coverage offered for specific drugs was off-label. From the available data, we could not determine which entity made the coverage decision - the patient assistance program or the drug manufacturer.

\section{DISCUSSION}

Independent charity patient assistance programs are playing an important role in the prescription drugs utilization. ${ }^{1}$ We found that they frequently provided assistance for off-label uses of high-cost drugs, and almost half of these uses were not supported by any of the three widely used clinical compendia. If patient assistance programs used other criteria to determine support for off-label uses, these alternative criteria were not disclosed. The clinical implications of off-label uses promoted by the financial assistance offered by these programs remain an important area for future research to explore.

Acknowledgements: The authors thank Vadi Esmailizadeh and Jingmiao Long for their research assistance.

Corresponding Author: So-Yeon Kang, MPH, MBA; Department of Health Policy and Management Bloomberg School of Public Health,
Johns Hopkins University, Baltimore, MD, USA (e-mail: skang57@jhu. edu).

Funding Information This study was funded by Arnold Ventures.

\section{Compliance with Ethical Standards:}

Conflict of Interest: The authors declare that they do not have a conflict of interest.

\section{REFERENCES}

1. Kang S, Sen A, Bai G, Anderson GF. Financial Eligibility Criteria and Medication Coverage for Independent Charity Patient Assistance Programs. JAMA. 2019;322(5):422-429. doi:https://doi.org/10.1001/jama. 2019.9943

2. Centers for Medicare \& Medicaid Services. Off-label pharmaceutical marketing: How to recognize and report it. Oct 2015. https://www.cms. gov/Medicare-Medicaid-Coordination/Fraud-Prevention/Medicaid-Integrity-Education/Downloads/off-label-marketing-factsheet.pdf. Accessed August 8, 2019

3. Klara K, Kim J, Ross JS. Direct-to-consumer broadcast advertisements for pharmaceuticals: off-label promotion and adherence to FDA guidelines. J Gen Intern Med. 2018;33(5):651-8.

4. Office of Inspector General. Advisory Opinion No. 10-07. U.S. Department of Health and Human Services web site. http://oig.hhs.gov/fraud/docs/ advisoryopinions/2010/AdvOpn10-07.pdf ("For a patient to qualify for assistance under the Proposed Arrangement, the Specialty Medication must have been prescribed as part of an approved course of treatment for a specified disease, and must not be for an off- label use.") Accessed August 8, 2019.

5. Office of Inspector General. Supplemental Special Advisory Bulletin: Independent Charity Patient Assistance Programs. Department of Health and Human Services Web site. https://oig.hhs.gov/fraud/docs/ alertsandbulletins/2014/independent-charity-bulletin.pdf Posted May 30, 2014. Accessed August 8, 2019.

6. Centers for Medicare \& Medicaid Services. Prescription drug benefit manual: Chapter 6-Part D drugs and formulary requirements. https:// www.cms.gov/Medicare/Prescription-Drug-Coverage/ PrescriptionDrugCovContra/PartDManuals.html. Published April 19, 2018. Accessed October 13, 2019

Publisher's Note Springer Nature remains neutral with regard to jurisdictional claims in published maps and institutional affiliations. 